\title{
The Effect of Water Temperature and Synoptic Winds on the Development of Surface Flows Over Narrow, Elongated Water Bodies
}

\author{
M. Segal AND R. A. Pielke \\ Department of Atmospheric Science, Colorado State University, Fort Collins
}

\begin{abstract}
Simulations of the thermally induced breeze involved with a relatively narrow, elongated water body is presented in conjunction with evaluations of sensible heat fluxes in a stable marine atmospheric surface layer. The effect of the water surface temperature and of the large-scale synoptic winds on the development of surface flows over the water is examined. As implied by the sensible heat flux patterns, the simulation results reveal the following trends: (1) When the synoptic flow is absent or light, the induced surface breeze is not affected noticeably by a reduction of the water surface temperature; (2) for stronger synoptic flow, the resultant surface flow may be significantly affected by the water surface temperature.
\end{abstract}

\section{INTRODUCTION}

Elongated and narrow water bodies (e.g., smaller than 20 $\mathrm{km}$ in width) are typical in many geographical locations. They consist, for example, of estuaries, bays, and natural and artificial lakes (the latter are mostly created by damming of a river). In these locations, a daytime induced breeze, including its interaction with the synoptic flow, may produce an involved pattern of surface flows. Evaluation of these patterns is of importance, for example, in considerations relating to wave characteristics and currents in the water body and in meteorological aspects such as local boating forecasts, air quality, ana heat load conditions during the warm season. The purpose of this paper is to suggest some insight into the local wind flow resulting from such water bodies (henceforth referred to as WB). Emphasis is given to the evaluation of the impact of the water surface temperature, and cross-WB synoptic flow intensity on the pattern of the WB surface flow. It is worth noting that the atmospheric-induced thermal circulations involved with such a WB differ from that of the sea, since the mesoscale available potential energy [see, e.g., Green and Dalu, 1980] is smaller, and therefore should be weaker as compared with the sea case. Additionally, the interaction with each other of breeze circulations induced by the opposite shores of the narrow WB, and their modification by the existing synoptic flows, are expected to produce more involved surface flow patterns as compared with those corresponding to the sea case.

The land-water surface temperature contrast is commonly used for a simplified scaling of lake/sea breeze intensity [e.g., Biggs and Graves, 1962; Lyons, 1972]. However, the sea breeze intensity is actually more closely related to the horizontal pressure gradient that is established due to the differential thermal heating at the surface and in the lower troposphere between the water and land bodies. It is the differential sensible heat flux that is generally most closely related to the magnitude and direction of the pressure gradient force generated during the day by land juxtaposed to water. Hence a conceptually better evaluation of the anticipated sea breeze intensity may be provided by estimating the differential sensible heat fluxes between the water and the land sections. In the present study we evaluate (and illustrate by a nomogram) sensible heat fluxes for a variety of stable sea-air temperature

Copyright 1985 by the American Geophysical Union.

Paper number $5 \mathrm{C} 0056$.

0148-0227/85/005C-0056\$05.00 gradients which may be involved with a relatively cold WB. They are compared against typical values of sensible heat fluxes over land surfaces, in order to provide a qualitative evaluation of the potential intensity of mesoscale circulations in such situations. Quantitative evaluations of the WB surface breeze in several synoptic flow cases are carried out by means of numerical model simulations.

\section{Sensible Heat Fiuxes Over Water AND LAND SURFACES}

Evaluation of the WB sensible heat fluxes $\left(H_{3}\right)$ and its cooling effects on the atmosphere has been performed using the functional relations given by Businger et al. [1971]. It consists of the following formulations:

$$
\begin{gathered}
H_{s}=\rho_{a} c_{p} u_{*} \theta_{*} \\
u_{*}=k_{0} V /\left[\ln \left(z / z_{0}\right)-\psi_{m}(z / L)\right] \\
\theta_{*}=k_{0}\left(\theta-\theta_{s}\right) /\left\{0.74\left[\ln \left(z / z_{0}\right)-\psi_{\theta}(z / L)\right]\right\}
\end{gathered}
$$

where

$c_{p}$ air specific heat at constant pressure;

$k_{0}$ the von Kármán constant;

$\theta_{s}$ potential temperature at the sea surface;

$\rho_{a}$ air density;

$z_{0} \quad$ water roughness parameter;

$z$ height above the water;

$L$ the Monin-Obukov length;

$u_{*}, \theta_{*}$ friction velocity and surface layer buoyant temperature, respectively;

$V, \theta$ wind speed and potential temperature, respectively; $\psi_{m}, \psi_{\theta}$ integrated profile functions within the surface layer.

The value of $z_{0}$ over the water was computed according to Clarke [1970], i.e.,

$$
z_{0}=0.032 u_{*}^{2} / g
$$

Neglecting laminar sublayer effects in the previous derivations may introduce some errors mostly for light winds; however, such refinement is not of importance in the context of the present study.

Based on relations (1)-(4), a nomogram (see Figure 1) was constructed to evaluate the characteristics of the heat flux as dependent on $V$ and $\Delta \theta=\theta-\theta_{s}$ (the surface water temperature was set as $26.8^{\circ} \mathrm{C}$ ). The levels for computation of $V$ and $\theta$ are 5 and $10 \mathrm{~m}$, respectively (the same as the lower computational levels for $V$ and $\theta$ in the model discussed in section 3). 


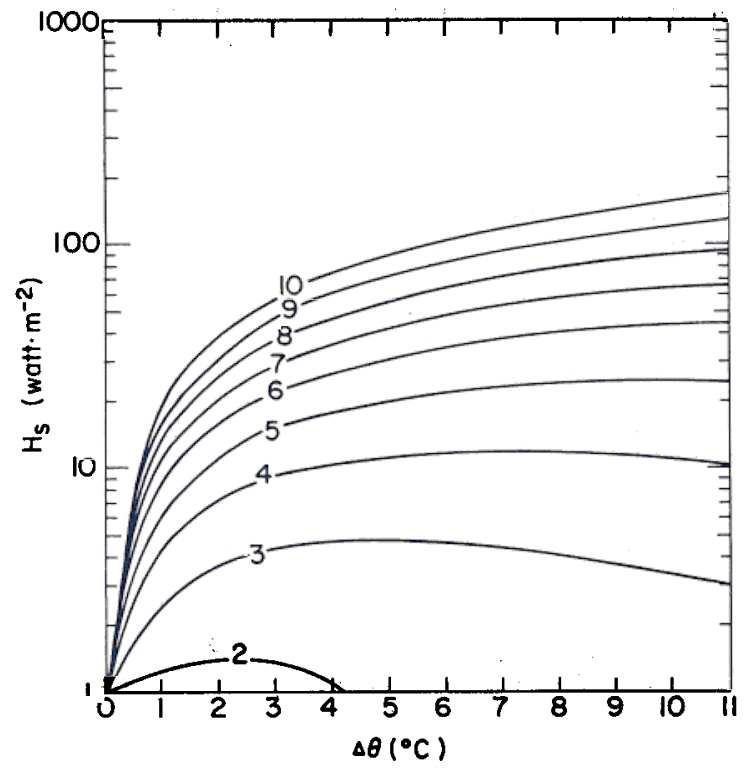

Fig. 1. The relation between sensible heat fluxes $\left(H_{3}\right)$ and various stable thermal stratification over water $(\Delta \theta)$ for a wind speed range of $2-10 \mathrm{~m} \mathrm{~s}^{-1}$.

The nomogram considers a stable atmospheric surface marine layer and will be related to the numerical simulations described in section 3 . Situations in which the surface air temperature may be significantly higher than the surface water temperature can be established, for example, due to upwelling, or due to offshore synoptic flows during the warm season crossing a relatively cold water body. The following general patterns are indicated by the nomogram:

1. At low wind speeds, the maximum rate of atmospheric cooling by the sensible heat flux exchange is obtained for moderate $\Delta \theta$ values. However, the magnitude of the sensible heat flux in this situation is relatively low.

2. As the wind speed intensifies, the atmospheric cooling increases monotonically. In the nomogram, for example, a sensible heat flux of $150 \mathrm{~W} \mathrm{~m} \mathrm{~m}^{-2}$ is computed for a wind speed of $10 \mathrm{~m} \mathrm{~s}^{-1}$ with $\Delta \theta=10^{\circ} \mathrm{C}$.

Computing a similar nomogram for the unstable surface layer over the land is not practical, since unlike a WB with a relatively deep thermocline, the surface temperature is not steady, and consideration of various $z_{0}$ values is needed. Hence we preferred to present typical values reported in the literature for the land values. Based on observations [e.g., Oke, 1978] and model studies [e.g., Sasamori, 1970; McCumber and Pielke, 1981], it is suggested that sensible heat fluxes over land during summer noon hours in the midlatitudes are generally within the range of $200-500 \mathrm{~W} \mathrm{~m}^{-2}$. Hence except for relatively strong surface winds, the sensible heat fluxes over a land surface during a sunny summer day in the midlatitudes are at least one order of magnitude or larger than those involved with water surfaces.
The characteristics of the sensible heat fluxes over water and land surfaces suggest that except for cases involving relatively strong synoptic flows, the cooling by sensible heat flux within the stable WB surface layer is of little importance in the development of the thermally forced breezes.

\section{Simulations}

Evaluation of the breeze with a narrow, elongated lake as a function of the synoptic flow intensity and the WB surface water temperature has been carried out by means of a twodimensional numerical mesoscale model (for its formulation, see Pielke [1974], Mahrer and Pielke [1977, 1978]). The land adjacent to the WB was considered to consist of relatively dry, bare soil. The input parameters are those tabulated by Mahrer and Pielke [1977]. The horizontal domain of simulation has been discretized using a horizontal grid interval of $3 \mathrm{~km}$, where 6 points represent the WB. In the vertical, 14 levels (with a top level at $7 \mathrm{~km}$ ) have been adopted (see Table 1 for level heights). The chosen meteorological input (Table 1) reflects summer conditions in the eastern Mediterranean area for temperature and moisture. Simulations were carried out for a WB with steady surface water temperatures, $T_{s}$, of either $27.5^{\circ} \mathrm{C}$ and $18.5^{\circ} \mathrm{C}$ for the following three geostrophic flow situations (with an initial planetary boundary layer top of 250 m): (1) no geostrophic flow; (2) geostrophic flow of $V_{g}=5 \mathrm{~m}$ $\mathrm{s}^{-1}$ crossing the WB; (3) same as situation 2 , however, with $V_{g}=10 \mathrm{~m} \mathrm{~s}^{-1}$. It is worth noting that the surface wind speed and direction in the last two cases differ from those of the geostrophic wind, as implied from the Ekman solution for the wind profile in the planetary boundary layer (PBL). In addition, in order to develop further insight into the role of sensible heat fluxes over the WB on the development of the WB breeze, test simulations in which thermal fluxes between the WB and the atmosphere were excluded in cases 1 and 3 were performed. All the simulations began at 0800 LST with the assumption of an initial horizontally homogeneous thermal stratification in the atmosphere throughout the whole domain. The flow at 5-m height at 1400 LST for these cases is presented in Figure 2. The patterns obtained indicate the following (the water surface temperature is always lower than that of the overlying air).

1. When $V_{g}=0$ (Figures $2 a-2 c$ ), there are only minor changes in the surface flow regardless of the surface water temperature. The negligible effect of WB surface temperature is reflected by the fact that the elimination of the heat fluxes over the WB produced the same pattern as in the regular simulations. Examining Figure 1 indicates that typical heat fluxes over the WB are less than $15 \mathrm{~W} \mathrm{~m}^{-2}$. On the other hand, typical computed heat fluxes over the land for that hour were around $300 \mathrm{~W} \mathrm{~m}^{-2}$, which explains the minor role that the fluxes over the WB has in the creation of an atmospheric thermal gradient (and consequently the pressure gradient) between the land and the water body.

2. With a geostrophic wind speed of $V_{g}=5 \mathrm{~m} \mathrm{~s}^{-1}$ in the simulated domain, sensible heat fluxes over the land are

TABLE 1. The Initial Vertical Profiles of the Temperature $(T)$ and the Specific Moisture $(q)$

\begin{tabular}{lrrrrrrrrrrrrrr}
\hline & \multicolumn{110}{c}{ Level, m } \\
\cline { 2 - 15 } & 10 & 32.5 & 75 & 200 & 400 & 600 & 800 & 1050 & 1350 & 1750 & 2500 & 4000 & 6000 & 7000 \\
\hline$T,{ }^{\circ} \mathrm{C}$ & 26.4 & 26.4 & 26.4 & 25.2 & 23.4 & 21.7 & 19.9 & 21.2 & 20.2 & 18.2 & 16.9 & 8.8 & -4.2 & -10.7 \\
$q, \mathrm{~g} / \mathrm{kg}$ & 17.2 & 16.9 & 16.9 & 15.0 & 14.0 & 13.0 & 8.5 & 8.0 & 5.5 & 4.2 & 1.2 & 1.2 & 1.2 & 1.2 \\
\hline
\end{tabular}


changed from the previous case with values at the presented hour on the order of $290-350 \mathrm{~W} \mathrm{~m}^{-2}$. Also a cooling effect of the WB with respect to Figures $2 a-2 c$ is implied by the flow patterns (Figures $2 d$ and $2 e$ ) and the nomogram. However, results indicate that the difference in cooling between the cool (Figure $2 d$ ) and less cool (Figure $2 e$ ) WB is insufficient to induce any major differences in the interaction of the WB breeze with the synoptic flow. In both cases some downstream shift of the lake circulation is evident, as compared with the $V_{g}=0$ cases.

The confluence of southwesterly surface synoptic flow with an about equally intense southeasterly induced lake breeze at the western wide of the WB produced, as expected, relatively strong southerly resultant flow. This type of flow pattern has been observed and modeled for wider WB cases [e.g., Strong, 1972; Physick, 1976; Estoque, 1981; Estoque and Gross, 1981].

3. The additional increase of the geostrophic flow $\left(V_{g}=10\right.$ $\mathrm{m} \mathrm{s}^{-1}$ ) produces a noticeable difference between the cool (Figure 2f) and less cool (Figure $2 g$ ) WB. The typical sensible heat fluxes over the land section remain similar to those in Figures $2 d$ and $2 e$. However, the cool WB atmosphere is affected by the sensible heat flow more than that of the less cool WB as a result of the greater difference between the water surface temperature and the overlying atmosphere. Hence in the cooler WB case the pattern of the breeze, which is shifted by the relatively strong synoptic flow in the downstream direction, is markedly evident in the figures. In the less cool WB case, however, the local wind breeze appears only as a perturbation to the synoptic flow, since it is not intense enough to oppose the relatively strong synoptic flow. Eliminating the fluxes over the WB (Figure $2 h$ ) reduces somewhat this perturbation. For case $h$ the thermal difference is established because of the lack of thermal interactions when the flow crosses the

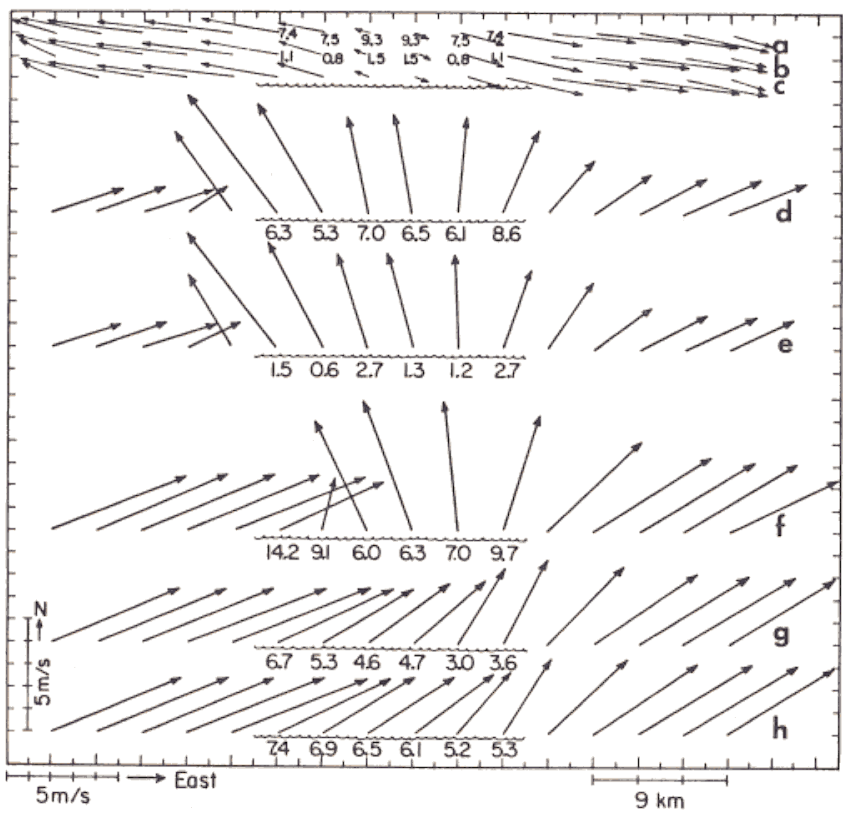

Fig. 2. Horizontal wind velocity patterns at 1400 LST at 5-m height. The wavy line indicates the WB. The values of $\Delta \theta$ over the WB defined as $\left[\theta_{10 \mathrm{~m}}-\theta_{\mathrm{s}}\right]$ are indicated in $\mathrm{C}$. The following cases are presented: (a) $V_{g}=0 ; T_{s}=18.5^{\circ} \mathrm{C},(b) V_{g}=0 ; T_{s}=27.5^{\circ} \mathrm{C},(c)$ $V_{g}=0$; no fluxes are considered over the WB, (d) $V_{g}=5 \mathrm{~m} \mathrm{~s}^{-1}$; $T_{s}=18.5^{\circ} \mathrm{C},(e) V_{g}=5 \mathrm{~m} \mathrm{~s}^{-1} ; T_{s}=27.5^{\circ} \mathrm{C},(f) V_{g}=10^{g} \mathrm{~m} \mathrm{~s}^{-1} ; T_{s}=$ $18.5^{\circ} \mathrm{C} ;(g) V_{g}=10 \mathrm{~m} \mathrm{~s}^{-1} ; T_{s}=27.5^{\circ} \mathrm{C} ;(h) V_{g}=10 \mathrm{~m} \mathrm{~s}^{-1}$; no fluxes are considered over the WB.
WB, while at the same time the onshore atmospheric thermal structure is modified by sensible heat fluxes.

\section{Summary AND CONClusions}

It has been shown that for relatively narrow, elongated cool water bodies, the effect of the water surface temperature on the development of the WB breeze is not important in the determination of the breeze intensity as long as the synoptic flow is not strong (and while assuming that at the onset of the breeze the thermal stratification is horizontally homogeneous). This pattern results since the cooling effect of the sensible heat fluxes on the stable atmospheric marine layer is negligible as compared with the corresponding warming effect over the land. Therefore it is suggested that in those cases the magnitude of the heating of the atmosphere over the land is the main factor in the determination of the breeze intensity associated with the WB. However, when the synoptic flow is relatively strong, increased sensible heat fluxes over the cold water are likely to enhance the WB breeze.

The symmetric flow pattern of the WB breeze in the absence of synoptic flow is distorted when cross-WB synoptic flow exists, shifting the lake breeze downstream with respect to the synoptic flow direction. For weak land-water surface temperature contrasts, even with strong synoptic flow, the WB breeze effect is evident only by a slight modification of the synoptic flow intensity while crossing the water.

Finally, the surrounding of the WB, which was considered in the present study to consist of relatively dry, bare soil, may in the real world consist of wet soil/vegetative cover (or a combination of both). Evaluation of such situations requires a more extended study. Generally, for these situations, suppression of the onshore sensible heat fluxes is expected. Hence the following qualitative modifications in the flow patterns presented in Figure 2 are suggested for these situations: (1) in Figures $2 a-2 c$ the SB intensity will be reduced; and (2) in Figures $2 d-2 h$ counterflows involved with the generation of the SB will be suppressed or eliminated.

Acknowledgments. This study was supported by National Science Foundation grants ATM 8304042 and ATM-8414181 and National Aeronautics and Space Administration grant NAG 5-359. The computations were carried out by the National Center for Atmospheric Research (NCAR) CRAY computer (NCAR is sponsored by the National Science Foundation). We would like to thank Sara Rumley for editing and typing the manuscript.

\section{REFERENCES}

Biggs, W. A., and M. E. Graves, A lake breeze index, J. Appl. Meteorol., 1, 474-480, 1962.

Businger, J. A., J. C. Wyngaard, Y. Izumi, and E. F. Bradley, Fluxprofile relationship in the atmospheric surface layer, J. Atmos. Sci., $28,181-189,1971$.

Clarke, R. H., Recommended methods for the treatment of the boundary layer in numerical models, Aust. Meteorol. Mag., 18, 51-73, 1970.

Estoque, M. A., Further studies of a lake breeze, 1, Observational study, Mon. Weather Rev., 109, 611-618, 1981.

Estoque, M. A., and J. M. Gross, Further studies of a lake breeze, 2, Theoretical study, Mon. Weather Rev., 109, 619-634, 1981.

Green, J. S. A. and G. A. Dalu, Mesoscale energy generated in the boundary layer, Q.J. R. Meteorol. Soc., 106, 721-726, 1980.

Lyons, W. A., The climatology and prediction of the Chicago lake breeze, J. Appl. Meteorol., 11, 1259-1270, 1972.

Mahrer, Y., and R. A. Pielke, A numerical study of the airflow over irregulár terrain, Beitr. Phys. Atmos., 50, 98-113, 1977.

Mahrer, Y., and R. A. Pielke, A test of an upstream spline interpolation technique for the advective terms in a numerical mesoscale model, Mon. Weather Rev., 106, 818-830, 1978. 
McCumber, M. C., and R. A. Pielke, Simulation of the effects of surface fluxes of heat and moisture in a mesoscale numerical model, 1, Soil model, J. Geophys. Res., 86, 9929-9938, 1981.

Oke, T. R., Boundary Layer Climates, 372 pp., Methuen, London, 1978.

Physick, W., A numerical model of sea-breeze phenomenon over lake or gulf, J. Atmos. Sci., 33, 2107-2135, 1976.

Pielke, R. A., A three-dimensional numerical model of the sea breezes over south Florida, Mon. Weather Rev., 102, 115-139, 1974.

Sasamori, T., A numerical study of atmospheric and soil boundary layers, J. Atmos. Sci., 27, 1117-1137, 1970.
Strong, A. E., The influence of a great lake anticyclone on the atmospheric circulation, J. Appl. Meteorol., 11, 598-612, 1972.

R. A. Pielke and M. Segal, Department of Atmospheric Science, Colorado State University, Fort Collins, CO 80523.

(Received September 22, 1984; accepted January 17, 1985.) 